\title{
BMJ Open How weight change is modelled in population studies can affect research findings: empirical results from a large-scale cohort study
}

\author{
E Paige, ${ }^{1}$ R J Korda, ${ }^{1}$ E Banks, ${ }^{1}$ B Rodgers ${ }^{2}$
}

To cite: Paige E, Korda RJ, Banks $\mathrm{E}$, et al. How weight change is modelled in population studies can affect research findings: empirical results from a large-scale cohort study. BMJ Open 2014:4:e004860.

doi:10.1136/bmjopen-2014004860

- Prepublication history for this paper is available online. To view these files please visit the journal online (http://dx.doi.org/10.1136/ bmjopen-2014-004860).

Received 14 January 2014 Revised 25 April 2014 Accepted 20 May 2014

\section{${ }^{1}$ National Centre for} Epidemiology and Population Health, Australian National University, Canberra, Australian Capital Territory, Australia

${ }^{2}$ Australian Demographic \& Social Research Institute, Australian National University, Canberra, Australian Capital Territory, Australia

Correspondence to Ellie Paige;

Ellie.Paige@anu.edu.au

\section{ABSTRACT}

Objectives: To investigate how results of the association between education and weight change vary when weight change is defined and modelled in different ways.

Design: Longitudinal cohort study.

Participants: 60404 men and women participating in the Social, Environmental and Economic Factors (SEEF) subcomponent of the 45 and Up Study-a population-based cohort study of people aged 45 years or older, residing in New South Wales, Australia.

Outcome measures: The main exposure was selfreported education, categorised into four groups. The outcome was annual weight change, based on change in self-reported weight between the 45 and Up Study baseline questionnaire and SEEF questionnaire (completed an average of 3.3 years later). Weight change was modelled in four different ways: absolute change (kg) modelled as (1) a continuous variable and (2) a categorical variable (loss, maintenance and gain), and relative $(\%)$ change modelled as (3) a continuous variable and (4) a categorical variable. Different cutpoints for defining weight-change categories were also tested.

Results: When weight change was measured categorically, people with higher levels of education (compared with no school certificate) were less likely to lose or to gain weight. When weight change was measured as the average of a continuous measure, a null relationship between education and annual weight change was observed. No material differences in the education and weight-change relationship were found when comparing weight change defined as an absolute $(\mathrm{kg})$ versus a relative $(\%)$ measure. Results of the logistic regression were sensitive to different cut-points for defining weight-change categories.

Conclusions: Using average weight change can obscure important directional relationship information and, where possible, categorical outcome measurements should be included in analyses.

\section{INTRODUCTION}

Obesity is a major global health problem. ${ }^{1}$ While there are numerous population studies that address the important question of what

\section{Strengths and limitations of this study}

First study to explore in depth and explicitly demonstrate how study outcomes differ when weight change is defined and modelled in different ways.

- Large sample size and heterogeneity across the primary exposure, allowing analysis of multiple education levels.

- Weight change calculated from self-reported weight, at two time points.

factors influence weight change, differences in methods, particularly in how weight change is defined and modelled, make it difficult to compare and integrate research results. ${ }^{2} 3$

There is no agreed definition of clinically significant weight change and research studies define and model weight change over time in a variety of ways. ${ }^{4}$ These include modelling weight change as either a continuous or categorical variable (or both); defining weight change as an absolute or relative change; and using different cut-points to define weight-change categories. It is unclear whether and to what extent these differences in defining and modelling weight change affect research findings.

The aim of our study is to investigate how research results vary when weight change is defined and modelled in different ways. To do this, we examine the association between education and weight change, where weight change is modelled in four different ways: absolute change ( $\mathrm{kg} /$ year) modelled as a continuous variable and as a categorical variable, and relative change (percentage change/ year) also modelled as a continuous variable and as a categorical variable. Further, we test the sensitivity of the results to different cutpoints for weight-change categories.

Education was chosen as the main sociodemographic factor of interest. While studies 
have shown that education is inversely associated with weight gain, there are inconsistencies in the results across studies. ${ }^{2}$ In addition, we explored the relationship of the various weight-change measures to other sociodemographic and behavioural factors.

\section{METHODS}

\section{Study population}

We used data from the 45 and Up Study baseline questionnaire, linked to data from the Social, Environmental and Economic Factors (SEEF) substudy questionnaire. The 45 and Up Study is an Australian cohort involving 267153 men and women aged 45 years and older from New South Wales, Australia. Participants in the study were randomly sampled from the database of Medicare Australia, which provides virtually complete coverage of the general population. Approximately $10 \%$ of the entire New South Wales population aged 45 years or older was included. Participants joined the study by completing a baseline questionnaire-distributed from January 2006 to December 2008-and giving signed consent for follow-up and linkage of their information to a range of health databases. The study is described in detail elsewhere, ${ }^{5}$ and questionnaires can be viewed at http://www.45andup.org.au.

Invitations to the SEEF substudy were sent to the first 100000 participants enrolled in the 45 and Up Study. Of those invited to complete the SEEF questionnaire (hereafter referred to as the follow-up questionnaire), 60404 participants did so, with questionnaires completed in 2010. Only participants who completed the 45 and Up Study baseline questionnaire and the follow-up questionnaire were included in the present analyses.

Consistent with previous studies on weight change, ${ }^{6} 7$ we excluded people with a history of cancer (excluding non-melanoma skin cancer) and those whose physical health severely limited them in walking $100 \mathrm{~m}$ at baseline. We further excluded participants with implausible values for height (outside the range of $121-213 \mathrm{~cm}^{8}$ ) and people with a body mass index (BMI) of $<15 \mathrm{~kg} \mathrm{~m}^{-2}$ or $>50 \mathrm{~kg} \mathrm{~m}^{-2}$ at baseline, as measurement error becomes more likely at these extreme values of BMI. ${ }^{9-11}$

\section{Measurements}

Exposure

Education was self-reported on the baseline questionnaire. Participants were asked about their highest completed qualification, with options including six categories from 'no school certificate or other qualification' to 'university degree or higher'. For this analysis, education was categorised as: 'no school certificate' (no school certificate or other qualification); 'school certificate' (school or intermediate certificate, or a higher school or leaving certificate, equivalent to completing secondary school); 'apprenticeship/diploma' (trade, apprenticeship, certificate or diploma); and 'university degree' (university degree or higher).

\section{Outcomes}

Participants self-reported their weight on the baseline and follow-up questionnaires. Change in weight from baseline to follow-up was the primary outcome. This was calculated as per annum weight change to account for varying follow-up time in the cohort and to enhance comparability with other studies which differ in follow-up length. Specifically, change in weight was calculated as weight $(\mathrm{kg})$ reported on the follow-up questionnaire minus weight $(\mathrm{kg})$ reported on the baseline questionnaire, divided by time (years) between completion of the baseline and follow-up questionnaires. Relative (percentage) change in weight was calculated as change in annual weight divided by weight at baseline, multiplied by 100 .

We modelled weight change as four different outcome variables:

1. Absolute annual weight change, modelled as a continuous variable

2. Absolute annual weight change, modelled as a categorical variable

3. Percentage annual weight change, modelled as a continuous variable

4. Percentage annual weight change, modelled as a categorical variable

For the categorical variables, participants were categorised as into groups of 'weight maintenance' (absolute weight change $\leq 1 \mathrm{~kg}$; or relative change $\leq 1.25 \%$ ), 'weight loss' (weight decrease $>1 \mathrm{~kg}$ or $1.25 \%$ ) or 'weight gain' (weight increase $>1 \mathrm{~kg}$ or $1.25 \%$ ). These cut-points were chosen based on those used in previous studies. ${ }^{6} 1213$

\section{Covariates}

Potential covariates in the relationship of education to weight change were identified a priori through a literature review and included age, sex, physical activity, physical impairment and smoking status. Information on these factors was self-reported on the baseline questionnaire. Physical activity was categorised as tertiles based on the weighted number of reported weekly sessions of walking, moderate activity and vigorous activity. ${ }^{14}$ Physical impairment was derived from responses to the Medical Outcomes Score-Physical Functioning (MOS-PF), which is equivalent to items from the physical functioning scale of the SF-36 health survey ${ }^{15}$ and was categorised as none/ minor (score of 75-100), moderate (score of 50-74) and severe (score of $<50$ ). Smoking status was categorised as never, past or current. In analyses of a change variable, it is generally considered inappropriate to adjust for the baseline measurement, ${ }^{16}{ }^{17}$ as such baseline weight was not used as a covariate in this study.

\section{Statistical methods}

Mean annual absolute and percentage weight change and the proportions of participants in each category of weight change (weight loss, weight maintenance and weight gain) were estimated in relation to the main variables. Differences between groups were compared using 
analysis of variance tests for mean weight change and $\chi^{2}$ tests for categorical weight change.

Multivariable linear and multinomial logistic regression models were used to estimate the strength of the relationship between education and weight change. For each model, unadjusted coefficients, sex- and age-adjusted coefficients and more fully adjusted coefficients (adjusted for covariates defined above) were calculated. We undertook four regression analyses, which differed only in outcome measure, and compared the results. We tested the assumptions of the two linear regression models and used robust standard errors to account for non-normality of the residuals. The exponentiated results of the multinomial logistic regression are reported. Unlike logistic regression which provides an odds ratio, the results of a multinomial logistic regression are estimated as relative risk ratios (RRRs). ${ }^{18}$ The RRR is interpreted as the relative risk of one outcome in relation to another outcome in the exposed group compared with the unexposed group.

To test the sensitivity to different cut-points, we re-ran the multinomial logistic regression models using cut-points of $2 \mathrm{~kg}, 3 \mathrm{~kg}, 3 \%$ and $5 \%$ per annum, which have been previously used in other studies. ${ }^{4}$ We then compared the regression coefficients across models using the different cut-points using Wald tests. ${ }^{18} 19$ In all analyses, $95 \%$ confidence intervals (CIs) were generated and, in line with previous studies, $\mathrm{p}$ values less than 0.05 were considered statistically different.

All analyses were performed using Stata V.12.0.

\section{RESULTS}

The final sample size was 45037 , after excluding those with a history of cancer $(n=9411)$, a severe limitation in the ability to walk $100 \mathrm{~m}(\mathrm{n}=964)$, missing education data $(n=673)$, missing data on weight $(n=1893)$ or height $(\mathrm{n}=1950)$, implausible height values $(\mathrm{n}=263)$ and BMI $<15$ or $>50 \mathrm{~kg} / \mathrm{m}^{2} \quad(\mathrm{n}=213)$. The mean time between the baseline and follow-up questionnaires was 3.3 years (range $=1.7-5.1$ years) .

Characteristics of the sample are presented in table 1 . Just over half the participants had either a university degree $(28 \%)$ or an apprenticeship/diploma qualification $(33 \%)$, while about a third $(30 \%)$ of the participants had a school certificate as their highest qualification and $9 \%$ had no school certificate.

\section{Factors associated with weight change}

Mean annual weight gain in the cohort was $0.24 \mathrm{~kg}$ overall and was higher in women $(0.27 \mathrm{~kg})$ than in men $(0.21 \mathrm{~kg})$. Overall, $60 \%$ of the sample maintained their weight ( $\leq 1 \mathrm{~kg}$ change), while $17 \%$ had an annual weight loss of $>1 \mathrm{~kg}$ and $23 \%$ (24\% of women and $22 \%$ of men) had an annual weight gain of $>1 \mathrm{~kg}$. In the univariate analysis, all factors were statistically associated with weight change, although weight change for physical functioning impairment was only statistically different when weight change was measured categorically (table 2 ).

Table 1 Characteristics of participants by education categories

\begin{tabular}{|c|c|c|c|c|}
\hline & \multicolumn{4}{|l|}{ Education level, \% (n) } \\
\hline & $\begin{array}{l}\text { No school certificate } \\
9 \%(n=3857)\end{array}$ & $\begin{array}{l}\text { School certificate } \\
30 \%(n=13635)\end{array}$ & $\begin{array}{l}\text { Trade/certificate/diploma } \\
33 \%(n=15059)\end{array}$ & $\begin{array}{l}\text { University degree or higher } \\
28 \%(n=12486)\end{array}$ \\
\hline \multicolumn{5}{|l|}{ Sex } \\
\hline Male & $43(1673)$ & $36(4951)$ & $54(8110)$ & $49(6177)$ \\
\hline Female & $57(2184)$ & $64(8684)$ & 46 (6949) & $51(6309)$ \\
\hline \multicolumn{5}{|l|}{ Age (years) } \\
\hline $45-54$ & 19 (722) & $27(3627)$ & $34(5104)$ & $45(5578)$ \\
\hline $55-64$ & $31(1178)$ & $36(4891)$ & $33(5004)$ & $33(4134)$ \\
\hline $65-74$ & $32(1228)$ & $24(3263)$ & 22 (3282) & $15(1846)$ \\
\hline $75-84$ & 17 (639) & $12(1624)$ & $10(1481)$ & $6(805)$ \\
\hline 85 plus & $2(90)$ & $2(230)$ & $1(188)$ & $1(123)$ \\
\hline \multicolumn{5}{|c|}{ Physical activity tertile } \\
\hline Low & $33(1235)$ & $28(3736)$ & 27 (3994) & $24(2931)$ \\
\hline Moderate & $34(1274)$ & 37 (4969) & $35(5261)$ & $36(4414)$ \\
\hline High & $33(1248)$ & $35(4755)$ & $38(5667)$ & $41(5081)$ \\
\hline \multicolumn{5}{|c|}{ Physical impairment } \\
\hline None/minor & $75(2352)$ & $84(10058)$ & $86(11688)$ & $92(10715)$ \\
\hline Moderate & 15 (459) & $11(1303)$ & 9 (1264) & $5(636)$ \\
\hline Severe & $11(335)$ & 5 (641) & $5(622)$ & $2(250)$ \\
\hline \multicolumn{5}{|l|}{ Smoking status } \\
\hline Never & $51(1960)$ & $59(8085)$ & 55 (8191) & 65 (8079) \\
\hline Past & $40(1532)$ & 34 (4591) & $39(5910)$ & $32(3920)$ \\
\hline Current & $9(347)$ & 7 (923) & $6(919)$ & $4(445)$ \\
\hline
\end{tabular}


Mean weight gain decreased with increasing age, and those aged 75 years or older had a mean weight loss. Participants with a healthy profile (high levels of physical activity or little to no physical impairment) generally had greater mean weight gain but were also more likely to have maintained their weight compared with those with less healthy profiles. Similarly, people with an apprenticeship/diploma or a university degree had a greater mean weight gain than those with a school certificate or no school certificate, but they also had a higher proportion of people maintaining their weight.

\section{Continuous versus categorical modelling of weight change}

The results of the linear regression analyses are shown in table 3. The unadjusted results show that, compared with people without a school certificate, those with a higher qualification gained slightly more weight annually. However, after adjusting for covariates, there was no statistical association between education level and annual weight change.
When weight change was modelled categorically, both the unadjusted and adjusted associations between education and weight change were statistically different (table 4). Compared with people with no school certificate, those with a school certificate, apprenticeship/ diploma or a university degree were less likely to lose weight and were less likely to gain weight, that is, they were more likely to have maintained their annual weight.

Results for the other variables included in the analyses also statistically differed when modelling weight change using continuous versus categorical variables (tables 5 and 6 ). Where a variable was associated with weight loss and weight gain, the results between the categorical and continuous outcomes differed. For example, participants with moderate or severe physical impairment (compared with no/minor physical impairment) and those who were past or current smokers (compared with never smokers) were statistically less likely to maintain their weight. However, when weight change was modelled as a continuous variable, no relationship between weight change and physical impairment and smoking was found.

Table 2 Mean annual weight change and proportion of participants by weight-change categories according to sample characteristics

\begin{tabular}{|c|c|c|c|c|c|c|c|}
\hline & \multirow[b]{2}{*}{$\mathbf{N}$} & \multirow{2}{*}{$\begin{array}{l}\text { Mean annual } \\
\text { weight } \\
\text { change (kg) }\end{array}$} & \multirow[b]{2}{*}{ p Value* } & \multicolumn{3}{|c|}{ Annual weight-change category } & \multirow[b]{2}{*}{ p Valuet } \\
\hline & & & & $\begin{array}{l}\text { Loss (\%) } \\
\mathrm{n}=7685(17 \%)\end{array}$ & $\begin{array}{l}\text { Maintenance (\%) } \\
\mathrm{n}=26922(60 \%)\end{array}$ & $\begin{array}{l}\text { Gain (\%) } \\
n=10430(23 \%)\end{array}$ & \\
\hline \multicolumn{8}{|l|}{ Sex } \\
\hline Male & 20911 & 0.21 & \multirow[t]{2}{*}{0.019} & 18 & 60 & 22 & \multirow[t]{2}{*}{$<0.001$} \\
\hline Female & 24126 & 0.27 & & 16 & 60 & 24 & \\
\hline \multicolumn{8}{|l|}{ Age (years) } \\
\hline $45-54$ & 15031 & 0.41 & \multirow[t]{5}{*}{$<0.001$} & 14 & 57 & 28 & \multirow[t]{5}{*}{$<0.001$} \\
\hline $55-64$ & 15207 & 0.26 & & 16 & 60 & 24 & \\
\hline $65-74$ & 9619 & 0.14 & & 18 & 63 & 19 & \\
\hline $75-84$ & 4549 & -0.07 & & 24 & 61 & 15 & \\
\hline 85 plus & 631 & -0.26 & & 32 & 56 & 13 & \\
\hline \multicolumn{8}{|l|}{ Education } \\
\hline No school cert & 3857 & 0.14 & \multirow[t]{4}{*}{0.016} & 22 & 54 & 25 & \multirow[t]{4}{*}{$<0.001$} \\
\hline School cert & 13635 & 0.23 & & 18 & 58 & 24 & \\
\hline Trade/cert/dip & 15059 & 0.28 & & 16 & 60 & 23 & \\
\hline University degree & 12486 & 0.24 & & 16 & 63 & 22 & \\
\hline \multicolumn{8}{|l|}{ Physical activity tertile } \\
\hline Low & 11896 & 0.19 & \multirow[t]{3}{*}{0.025} & 19 & 56 & 25 & \multirow[t]{3}{*}{$<0.001$} \\
\hline Moderate & 15918 & 0.25 & & 17 & 60 & 23 & \\
\hline High & 16751 & 0.27 & & 15 & 62 & 22 & \\
\hline \multicolumn{8}{|c|}{ Physical impairment } \\
\hline None/minor & 34813 & 0.25 & \multirow[t]{3}{*}{0.080} & 16 & 62 & 23 & \multirow[t]{3}{*}{$<0.001$} \\
\hline Moderate & 3662 & 0.21 & & 22 & 53 & 25 & \\
\hline Severe & 1848 & 0.13 & & 26 & 46 & 28 & \\
\hline \multicolumn{8}{|l|}{ Smoking status } \\
\hline Never & 26315 & 0.21 & \multirow[t]{3}{*}{$<0.001$} & 16 & 62 & 22 & \multirow[t]{3}{*}{$<0.001$} \\
\hline Past & 15953 & 0.25 & & 18 & 58 & 24 & \\
\hline Current & 2634 & 0.50 & & 18 & 49 & 33 & \\
\hline $\begin{array}{l}{ }^{*} \mathrm{p} \text { Value of analysis of } \\
\mathrm{tp} \text { Value of } \chi^{2} \text { tests. } \\
\text { Physical impairment } \\
\text { physical functioning sca } \\
\text { weight change is define } \\
\text { Weight gain is defined }\end{array}$ & $\begin{array}{l}\text { iance te } \\
\text { neasure } \\
\text { of the } S \\
\text { as an an }\end{array}$ & $\begin{array}{l}\text { sing the Medice } \\
6 \text { health survey } \\
\text { l weight chang }\end{array}$ & $\begin{array}{l}\text { Dutcomes } \\
\text { one/minc } \\
\text { f betwee }\end{array}$ & $\begin{array}{l}\text { core-Physical Fu } \\
\text { score of } 75-100 \\
-1 \text { and } 1 \mathrm{~kg} \text {. Wei }\end{array}$ & $\begin{array}{l}\text { oning (MOS-PF), whi } \\
\text { derate=score of } 50- \\
\text { loss is defined as }>-\end{array}$ & $\begin{array}{l}\text { h is equivalent to ite } \\
4 ; \text { and severe=score } \\
\mathrm{kg} \text { annual weight } \mathrm{cl}\end{array}$ & $\begin{array}{l}\text { ns from the } \\
\text { of }<50) \text {. No } \\
\text { ange. }\end{array}$ \\
\hline
\end{tabular}


Table 3 Relationship of education level to annual change in weight, measured as a continuous variable

\begin{tabular}{|c|c|c|c|c|c|c|}
\hline & \multicolumn{3}{|c|}{ Annual weight change (kg) } & \multicolumn{3}{|c|}{ Annual weight change (\%) } \\
\hline & $\boldsymbol{\beta}$ & $95 \% \mathrm{Cl}$ & p Value & $\boldsymbol{\beta}$ & $95 \% \mathrm{Cl}$ & p Value \\
\hline \multicolumn{7}{|l|}{ Unadjusted } \\
\hline No school cert & 0.00 & - & - & 0.00 & - & - \\
\hline School cert & 0.08 & -0.01 to 0.17 & 0.076 & 0.08 & -0.04 to 0.20 & 0.179 \\
\hline Trade/cert/dip & 0.14 & 0.05 to 0.23 & 0.003 & 0.16 & 0.04 to 0.27 & 0.011 \\
\hline University degree & 0.09 & 0.00 to 0.18 & 0.048 & 0.09 & -0.03 to 0.21 & 0.128 \\
\hline \multicolumn{7}{|l|}{ Adjusted ${ }^{*}$} \\
\hline No school cert & 0.00 & - & - & 0.00 & - & - \\
\hline School cert & 0.04 & -0.05 to 0.13 & 0.387 & 0.02 & -0.10 to 0.14 & 0.717 \\
\hline Trade/cert/dip & 0.08 & -0.02 to 0.17 & 0.103 & 0.08 & -0.04 to 0.20 & 0.190 \\
\hline University degree & -0.01 & -0.10 to 0.09 & 0.874 & -0.04 & -0.16 to 0.09 & 0.572 \\
\hline \multicolumn{7}{|l|}{ Adjusted $†$} \\
\hline No school cert & 0.00 & - & - & 0.00 & - & - \\
\hline School cert & 0.02 & -0.08 to 0.11 & 0.753 & -0.01 & -0.14 to 0.11 & 0.846 \\
\hline Trade/cert/dip & 0.07 & -0.02 to 0.17 & 0.141 & 0.07 & -0.06 to 0.20 & 0.264 \\
\hline University degree & -0.01 & -0.11 to 0.09 & 0.814 & -0.04 & -0.17 to 0.09 & 0.567 \\
\hline
\end{tabular}

*Sex-adjusted and age-adjusted only.

†Adjusted for age group, sex, physical activity, physical impairment and smoking status.

\section{Absolute versus relative weight change measures}

The overall association between education and weight change did not differ materially when weight change was measured as a relative $(\% /$ year $)$ variable rather than as an absolute variable ( $\mathrm{kg}$ /year; tables 5 and 6$)$, with one exception. When modelled as a categorical variable (table 6), the direction and magnitude of the effect size for sex changed between the absolute weight and relative weight measures. For weight loss, when measured as an absolute change, women were less likely to have lost weight than men, but when measured as a relative change they were more likely to have lost weight. For weight gain, there was no significant sex effect when measured as an absolute change, but when measured as a relative change, women were more $50 \%$ more likely to gain weight than men. Notably, women had a lower mean starting weight compared with men $(69.7 \mathrm{~kg}$ compared with $83.9 \mathrm{~kg}$ ); thus, for a given value of absolute weight change, the percentage change in weight was higher in women compared with men. For all other variables, mean baseline weight was similar between groups and there were no material differences observed between absolute and relative measures.

\section{Sensitivity of categorical cut-points}

The results of the logistic regression using different cutpoints to define weight-change categories are presented in tables 7 and 8 . Using the $2 \mathrm{~kg}$ cut-point, $6.57 \%$ $(\mathrm{n}=2959)$ of participants were in the weight-loss category and $8.98 \% \quad(\mathrm{n}=4043)$ were in the weight-gain category, while a $3 \mathrm{~kg}$ cut-point decreased the proportions to $3.21 \% \quad(\mathrm{n}=1446)$ and $4.29 \% \quad(\mathrm{n}=1933)$, respectively. When a $3 \%$ cut-point was used to categorise weight change, $4.89 \% \quad(n=2203)$ of participants were in the weight-loss group and $7.49 \% \quad(n=3374)$ were in the weight-gain group, while the corresponding proportions for a cut-point of $5 \%$ were $1.49 \% \quad(n=669)$ and $2.63 \%$ (1186). Those with a school certificate, apprenticeship/ diploma or university degree were still more likely to maintain their annual weight than those with no school certificate, but this was no longer statistically different for some education levels based on the 5\% cut-point, possibly due to smaller numbers in these groups $(<5 \%$ of the sample were in the weight-loss and weight-gain groups). Formal testing of the differences in effect sizes using different cut-points showed that they statistically differed in magnitude, but not direction, from the results of the main logistic regression analyses $(p<0.001)$, except for weight loss using the $2 \mathrm{~kg}$ cutpoint $(\mathrm{p}=0.097)$.

\section{DISCUSSION}

\section{Principal findings}

Weight change in this middle-aged cohort of Australians was common, with $23 \%$ of people gaining weight and $17 \%$ losing weight during the follow-up period. This study shows that observed relationships of exposures to weight change can vary according to how weight change is defined and modelled. Specifically, when weight change was measured as the average of a continuous variable, we found no statistical association between education and weight change. However, when weight change was modelled as a categorical variable, we found that people with higher levels of education (compared with no school certificate) were more likely to maintain their weight annually within $1 \mathrm{~kg}$ or $1.25 \%$ of their baseline weight-they were less likely to lose weight or gain weight. For other factors where participants were both more likely to lose and gain weight, we found similar differences in results when weight change was modelled as 
Table 4 Relative risk ratios (RRRs) of annual weight loss compared to weight maintenance, and annual weight gain compared to weight maintenance, according to education levels

\begin{tabular}{|c|c|c|c|c|c|c|c|c|}
\hline & \multicolumn{2}{|c|}{$\begin{array}{l}\text { RRR for annual weight loss } \\
>1 \mathrm{~kg} \text { compared to weight } \\
\text { maintenance }\end{array}$} & \multicolumn{2}{|c|}{$\begin{array}{l}\text { RRR for annual weight loss } \\
>1.25 \% \text { compared to weight } \\
\text { maintenance }\end{array}$} & \multicolumn{2}{|c|}{$\begin{array}{l}\text { RRR for annual weight gain } \\
>1 \mathrm{~kg} \text { compared to weight } \\
\text { maintenance }\end{array}$} & \multicolumn{2}{|c|}{$\begin{array}{l}\text { RRR for annual weight gain } \\
>1.25 \% \text { compared to weight } \\
\text { maintenance }\end{array}$} \\
\hline & $\overline{R R R ~(95 \% ~ C l) ~}$ & p Value & RRR (95\% Cl) & p Value & $\overline{R R R ~(95 \% ~ C l) ~}$ & p Value & $\overline{R R R ~(95 \% ~ C I) ~}$ & p Value \\
\hline \multicolumn{9}{|l|}{ Unadjusted } \\
\hline No school cert & 1.00 & - & 1.00 & - & 1.00 & - & 1.00 & - \\
\hline School cert & 0.75 (0.68 to 0.82$)$ & $<0.001$ & 0.75 (0.69 to 0.83$)$ & $<0.001$ & 0.90 (0.82 to 0.98$)$ & 0.014 & $0.92(0.84$ to 1.00$)$ & 0.053 \\
\hline Trade/cert/dip & $0.68(0.62$ to 0.74$)$ & $<0.001$ & 0.65 (0.60 to 0.72$)$ & $<0.001$ & 0.85 (0.78 to 0.93$)$ & $<0.001$ & 0.84 (0.77 to 0.92$)$ & $<0.001$ \\
\hline University degree & 0.62 (0.56 to 0.68$)$ & $<0.001$ & 0.61 (0.56 to 0.67$)$ & $<0.001$ & 0.76 (0.69 to 0.83$)$ & $<0.001$ & 0.77 (0.71 to 0.85$)$ & $<0.001$ \\
\hline \multicolumn{9}{|l|}{ Adjusted $^{*}$} \\
\hline No school cert & 1.00 & - & 1.00 & - & 1.00 & - & 1.00 & - \\
\hline School cert & 0.77 (0.71 to 0.85$)$ & $<0.001$ & $0.77(0.70$ to 0.85$)$ & $<0.001$ & $0.83(0.76$ to 0.91$)$ & $<0.001$ & 0.84 (0.77 to 0.92$)$ & $<0.001$ \\
\hline Trade/cert/dip & 0.70 (0.64 to 0.77$)$ & $<0.001$ & 0.72 (0.65 to 0.79$)$ & $<0.001$ & $0.76(0.70$ to 0.83$)$ & $<0.001$ & 0.80 (0.73 to 0.87$)$ & $<0.001$ \\
\hline University degree & 0.66 (0.60 to 0.73$)$ & $<0.001$ & $0.68(0.62$ to 0.75$)$ & $<0.001$ & $0.64(0.58$ to 0.70$)$ & $<0.001$ & $0.68(0.62$ to 0.74$)$ & $<0.001$ \\
\hline \multicolumn{9}{|l|}{ Adjusted $†$} \\
\hline No school cert & 1.00 & - & 1.00 & - & 1.00 & - & 1.00 & - \\
\hline School cert & $0.84(0.76$ to 0.93$)$ & 0.001 & $0.82(0.73$ to 0.91$)$ & $<0.001$ & 0.88 (0.80 to 0.97$)$ & 0.014 & 0.87 (0.79 to 0.96$)$ & 0.005 \\
\hline Trade/cert/dip & 0.76 (0.68 to 0.84$)$ & $<0.001$ & 0.76 (0.69 to 0.84$)$ & $<0.001$ & $0.80(0.73$ to 0.89$)$ & $<0.001$ & $0.82(0.75$ to 0.91$)$ & $<0.001$ \\
\hline University degree & 0.76 (0.68 to 0.85$)$ & $<0.001$ & $0.76(0.69$ to 0.85$)$ & $<0.001$ & $0.72(0.65$ to 0.80$)$ & $<0.001$ & 0.74 (0.67 to 0.82$)$ & $<0.001$ \\
\hline
\end{tabular}


Table 5 Relationship of baseline characteristics (excluding education) to annual change in weight, measured as a continuous variable

\begin{tabular}{|c|c|c|c|c|c|c|}
\hline & \multicolumn{3}{|c|}{ Annual weight change (kg) } & \multicolumn{3}{|c|}{ Annual weight change (\%) } \\
\hline & $\mathbf{B}^{*}$ & $95 \% \mathrm{Cl}$ & p Value & $\boldsymbol{\beta}^{*}$ & $95 \% \mathrm{Cl}$ & p Value \\
\hline \multicolumn{7}{|l|}{ Sex } \\
\hline Male & 0.00 & - & - & 0.00 & - & - \\
\hline Female & 0.02 & -0.03 to 0.07 & 0.498 & 0.09 & 0.03 to 0.16 & 0.004 \\
\hline \multicolumn{7}{|l|}{ Age (years) } \\
\hline $45-54$ & 0.00 & - & - & 0.00 & - & - \\
\hline $55-64$ & -0.14 & -0.20 to -0.09 & $<0.001$ & -0.19 & -0.26 to -0.12 & $<0.001$ \\
\hline $65-74$ & -0.28 & -0.35 to -0.21 & $<0.001$ & -0.36 & -0.45 to -0.27 & $<0.001$ \\
\hline $75-84$ & -0.47 & -0.57 to -0.36 & $<0.001$ & -0.62 & -0.76 to -0.48 & $<0.001$ \\
\hline 85 plus & -0.83 & -1.00 to -0.66 & $<0.001$ & -1.14 & -1.40 to -0.88 & $<0.001$ \\
\hline \multicolumn{7}{|c|}{ Physical activity tertile } \\
\hline Low & 0.00 & - & - & 0.00 & - & - \\
\hline Moderate & 0.06 & 0.00 to 0.12 & 0.053 & 0.06 & -0.02 to 0.14 & 0.128 \\
\hline High & 0.06 & 0.00 to 0.12 & 0.038 & 0.07 & 0.00 to 0.15 & 0.066 \\
\hline \multicolumn{7}{|c|}{ Physical impairment } \\
\hline None/minor & 0.00 & - & - & 0.00 & - & - \\
\hline Moderate & 0.05 & -0.05 to 0.15 & 0.290 & 0.04 & -0.08 to 0.16 & 0.534 \\
\hline Severe & 0.00 & -0.13 to 0.13 & 0.959 & 0.00 & -0.17 to 0.16 & 0.956 \\
\hline \multicolumn{7}{|l|}{ Smoking status } \\
\hline Never & 0.00 & - & - & 0.00 & - & - \\
\hline Past & 0.03 & -0.02 to 0.08 & 0.278 & 0.04 & -0.03 to 0.11 & 0.250 \\
\hline Current & 0.26 & 0.14 to 0.38 & $<0.001$ & 0.40 & 0.23 to 0.56 & $<0.001$ \\
\hline
\end{tabular}

${ }^{*}$ Mutually adjusted for other variables listed in table and education.

Physical impairment was measured using the Medical Outcomes Score-Physical Functioning (MOS-PF), which is equivalent to items from the physical functioning scale of the SF-36 health survey (none/minor=score of $75-100$; moderate=score of $50-74$; and severe=score of $<50$ ).

a continuous rather than categorical variable. Further, we found that the results of the logistic regression were also sensitive to different cut-points for defining weight-change categories.

\section{Strengths and weaknesses of this study}

The main strength of this study is the large sample size and heterogeneity across the primary exposure allowing different levels of education to be examined. There are three important limitations to our study. First, weight change was calculated from self-reported weight at baseline and follow-up. It is well established that people tend to underestimate their weight when self-reporting. ${ }^{20} \mathrm{~A}$ validation study using participants from the 45 and Up Study found a high correlation between the self-reported and measured weight $(r=0.99),{ }^{21}$ suggesting that the effect estimates calculated from these self-reported data are still likely to be valid. Unpublished data from the weight validation study ${ }^{21}$ within the 45 and Up Study demonstrated that while people on average under-report their weight, there was no significant difference in the mean discrepancy between measured and self-reported weight according to education level. Further, if people underestimated their weight by approximately the same amount at both time points, there will be minimal to no bias in the change measurement. However, it is acknowledged that if precision in reporting weight change, and hence variance, varies by education level, this itself could at least partly account for the observed differences between the categorical versus continuous weight change measures. This is because the greater the variation, the higher the probability there is of crossing the upper and lower thresholds for defining weight change, while mean weight change remains unaffected.

We further note that the overall mean weight change observed in the participants $(0.24 \mathrm{~kg} /$ year $)$ is small and falls within the expected error margins. Second, weight was reported at only two time points; thus, the observed weight change may be due to regression to the mean. However, the majority of previous studies also analysed data from two time points only and the purpose of this study was to use similar techniques to previous studies in order to compare results when using different outcome measures, not to estimate the actual strength of the association between education and weight change. Third, height was only recorded at baseline and as such we could not examine change in BMI. While height at follow-up was not reported, the short follow-up time (mean 3.3 years) means that no material change in height would be expected in the cohort as height generally remains stable in adults over this time period (except in the very elderly). Given this, and the fact that weight change and BMI change are mathematically equivalent when height is constant, ${ }^{4}$ these findings can be applied to studies examining change in BMI in situations where height remains constant over time. 
Table 6 Adjusted* relative risk ratios (RRRs) of annual weight loss compared to weight maintenance and annual weight gain compared to weight maintenance according to other sample characteristics

\begin{tabular}{|c|c|c|c|c|c|c|c|c|}
\hline & \multicolumn{2}{|c|}{$\begin{array}{l}\text { RRR for annual weight loss } \\
>1 \mathrm{~kg} \text { compared to weight } \\
\text { maintenance }\end{array}$} & \multicolumn{2}{|c|}{$\begin{array}{l}\text { RRR for annual weight loss } \\
>1.25 \% \text { compared to weight } \\
\text { maintenance }\end{array}$} & \multicolumn{2}{|c|}{$\begin{array}{l}\text { RRR for annual weight gain } \\
>1 \mathrm{~kg} \text { compared to weight } \\
\text { maintenance }\end{array}$} & \multicolumn{2}{|c|}{$\begin{array}{l}\text { RRR for annual weight gain } \\
>1.25 \% \text { compared to weight } \\
\text { maintenance }\end{array}$} \\
\hline & RRR $(95 \% \mathrm{Cl})^{\star}$ & p Value & RRR $(95 \%$ Cl) & $p$ Value & RRR (95\% Cl)* & $p$ Value & RRR $(95 \% \mathrm{Cl})^{\star}$ & $p$ Value \\
\hline \multicolumn{9}{|l|}{ Sex } \\
\hline Male & 1.00 & - & 1.00 & - & 1.00 & - & 1.00 & - \\
\hline Female & 0.92 (0.87 to 0.98$)$ & 0.007 & 1.31 (1.24 to 1.39$)$ & $<0.001$ & $1.03(0.98$ to 1.09$)$ & 0.216 & 1.48 (1.41 to 1.56$)$ & $<0.001$ \\
\hline \multicolumn{9}{|l|}{ Age } \\
\hline $45-54$ & 1.00 & - & 1.00 & - & 1.00 & - & 1.00 & - \\
\hline $55-64$ & 1.05 (0.98 to 1.13 ) & 0.133 & 1.03 (0.97 to 1.11$)$ & 0.331 & 0.79 (0.74 to 0.83$)$ & $<0.001$ & 0.76 (0.72 to 0.81$)$ & $<0.001$ \\
\hline $65-74$ & 1.05 (0.97 to 1.13 ) & 0.236 & 1.09 (1.01 to 1.18$)$ & 0.030 & $0.56(0.52$ to 0.60$)$ & $<0.001$ & 0.58 (0.54 to 0.62$)$ & $<0.001$ \\
\hline $75-84$ & 1.23 (1.11 to 1.36$)$ & $<0.001$ & 1.50 (1.36 to 1.66$)$ & $<0.001$ & $0.39(0.35$ to 0.44$)$ & $<0.001$ & 0.48 (0.43 to 0.53$)$ & $<0.001$ \\
\hline 85plus & 1.54 (1.24 to 1.92$)$ & $<0.001$ & 2.23 (1.80 to 2.76$)$ & $<0.001$ & $0.29(0.21$ to 0.40$)$ & $<0.001$ & 0.44 (0.33 to 0.59$)$ & $<0.001$ \\
\hline \multicolumn{9}{|c|}{ Physical activity tertile } \\
\hline Low & 1.00 & - & 1.00 & - & 1.00 & - & 1.00 & - \\
\hline Moderate & 0.86 (0.80 to 0.92$)$ & $<0.001$ & 0.89 (0.83 to 0.96$)$ & 0.001 & 0.88 (0.83 to 0.94$)$ & $<0.001$ & 0.91 (0.86 to 0.97 ) & 0.004 \\
\hline High & 0.77 (0.72 to 0.83 ) & $<0.001$ & 0.85 (0.79 to 0.91$)$ & $<0.001$ & 0.84 (0.79 to 0.89$)$ & $<0.001$ & 0.93 (0.87 to 0.99$)$ & 0.015 \\
\hline \multicolumn{9}{|c|}{ Physical impairment } \\
\hline None/minor & 1.00 & - & 1.00 & - & 1.00 & - & 1.00 & - \\
\hline Moderate & 1.49 (1.36 to 1.64$)$ & $<0.001$ & 1.33 (1.21 to 1.45$)$ & $<0.001$ & 1.44 (1.32 to 1.57$)$ & $<0.001$ & 1.25 (1.14 to 1.36$)$ & $<0.001$ \\
\hline Severe & 1.88 (1.67 to 2.12 ) & $<0.001$ & 1.69 (1.49 to 1.90$)$ & $<0.001$ & 1.82 (1.62 to 2.05$)$ & $<0.001$ & 1.60 (1.42 to 1.80$)$ & $<0.001$ \\
\hline \multicolumn{9}{|c|}{ Smoking status } \\
\hline Never & 1.00 & - & 1.00 & - & 1.00 & - & 1.00 & - \\
\hline Past & 1.21 (1.14 to 1.29 ) & $<0.001$ & 1.18 (1.12 to 1.26$)$ & $<0.001$ & $1.19(1.13$ to 1.26$)$ & $<0.001$ & 1.15 (1.09 to 1.21$)$ & $<0.001$ \\
\hline Current & 1.39 (1.23 to 1.57$)$ & $<0.001$ & 1.51 (1.34 to 1.71$)$ & $<0.001$ & 1.74 (1.57 to 1.92$)$ & $<0.001$ & 1.78 (1.61 to 1.96$)$ & $<0.001$ \\
\hline
\end{tabular}

${ }^{*}$ Mutually adjusted for other variables listed in the table and for education.

Notes: Physical impairment was measured using the Medical Outcomes Score-Physical Functioning (MOS-PF), which is equivalent to items from the physical functioning scale of the SF-36 health survey (none/minor=score of $75-100$; moderate=score of $50-74$; and severe=score of $<50$ ). 
Table 7 Sensitivity analysis-adjusted* relative risk ratios (RRRs) of annual weight loss compared to weight maintenance and annual weight gain compared to weight maintenance according to education levels using alternative cut-points of $2 \mathrm{~kg}$ and $3 \mathrm{~kg}$

\begin{tabular}{|c|c|c|c|c|c|c|c|c|}
\hline & \multicolumn{2}{|c|}{$\begin{array}{l}\text { RRR for annual weight loss } \\
>2 \mathrm{~kg} \text { compared to weight } \\
\text { maintenance }\end{array}$} & \multicolumn{2}{|c|}{$\begin{array}{l}\text { RRR for annual weight loss } \\
>3 \mathbf{~ k g} \text { compared to weight } \\
\text { maintenance }\end{array}$} & \multicolumn{2}{|c|}{$\begin{array}{l}\text { RRR for annual weight gain } \\
>2 \mathrm{~kg} \text { compared to weight } \\
\text { maintenance }\end{array}$} & \multicolumn{2}{|c|}{$\begin{array}{l}\text { RRR for annual weight gain } \\
>3 \mathbf{k g} \text { compared to weight } \\
\text { maintenance }\end{array}$} \\
\hline & $\overline{\operatorname{RRR}(95 \% \mathrm{CI})^{\star}}$ & p Value & $\overline{\operatorname{RRR}(95 \% \mathrm{Cl}) \text { * }}$ & p Value & $\overline{\operatorname{RRR}(95 \% \mathrm{Cl}) \text { * }}$ & p Value & $\overline{\operatorname{RRR}(95 \% \mathrm{Cl}) \text { * }}$ & p Value \\
\hline No school cert & 1.00 & - & 1.00 & - & 1.00 & - & 1.00 & - \\
\hline School cert & 0.84 (0.72 to 0.97$)$ & 0.017 & 0.80 (0.65 to 0.98$)$ & 0.031 & 0.81 (0.71 to 0.92$)$ & 0.002 & 0.75 (0.62 to 0.90$)$ & 0.002 \\
\hline Trade/cert/dip & $0.74(0.64$ to 0.86$)$ & $<0.001$ & 0.71 (0.58 to 0.87$)$ & 0.001 & $0.79(0.69$ to 0.90$)$ & $<0.001$ & $0.79(0.66$ to 0.94$)$ & 0.009 \\
\hline University degree & 0.75 (0.64 to 0.87$)$ & $<0.001$ & 0.77 (0.62 to 0.95$)$ & 0.017 & 0.64 (0.56 to 0.74$)$ & $<0.001$ & $0.62(0.51$ to 0.75$)$ & $<0.001$ \\
\hline
\end{tabular}

${ }^{*}$ Adjusted for age group, sex, physical activity, physical impairment and smoking status.

Table 8 Sensitivity analysis-adjusted* relative risk ratios (RRRs) of annual weight loss compared to weight maintenance and annual weight gain compared to weight maintenance according to education levels using alternative cut-points of $3 \%$ and $5 \%$

\begin{tabular}{|c|c|c|c|c|c|c|c|c|}
\hline & \multicolumn{2}{|c|}{$\begin{array}{l}\text { RRR for annual weight loss } \\
>3 \% \text { compared to weight } \\
\text { maintenance }\end{array}$} & \multicolumn{2}{|c|}{$\begin{array}{l}\text { RRR for annual weight loss } \\
>5 \% \text { compared to weight } \\
\text { maintenance }\end{array}$} & \multicolumn{2}{|c|}{$\begin{array}{l}\text { RRR for annual weight gain } \\
>3 \% \text { compared to weight } \\
\text { maintenance }\end{array}$} & \multicolumn{2}{|c|}{$\begin{array}{l}\text { RRR for annual weight gain } \\
>5 \% \text { compared to weight } \\
\text { maintenance }\end{array}$} \\
\hline & $\overline{\operatorname{RRR}(95 \% \mathrm{Cl})^{\star}}$ & p Value & $\overline{\operatorname{RRR}(95 \% \mathrm{CI})^{*}}$ & p Value & 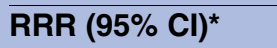 & p Value & $\overline{\operatorname{RRR}(95 \% \mathrm{CI})^{\star}}$ & p Value \\
\hline No school cert & 1.00 & - & 1.00 & - & 1.00 & - & 1.00 & - \\
\hline School cert & $0.83(0.71$ to 0.98$)$ & 0.032 & 0.84 (0.63 to 1.12$)$ & 0.235 & 0.79 (0.69 to 0.91$)$ & 0.001 & 0.74 (0.59 to 0.93$)$ & 0.010 \\
\hline Trade/cert/dip & 0.71 (0.60 to 0.85$)$ & $<0.001$ & 0.67 (0.50 to 0.89$)$ & 0.007 & 0.81 (0.71 to 0.94$)$ & 0.004 & 0.84 (0.67 to 1.04$)$ & 0.114 \\
\hline University degree & $0.76(0.63$ to 0.90$)$ & 0.002 & $0.69(0.50$ to 0.94$)$ & 0.019 & 0.65 (0.56 to 0.75$)$ & $<0.001$ & 0.65 (0.51 to 0.83$)$ & 0.001 \\
\hline
\end{tabular}




\section{Strengths and weaknesses of the study in relation to other} studies

We are not aware of any studies that have explicitly tested whether differences in the modelling of weight change can affect research findings. However, two previous studies ${ }^{22} 23$ used data from the United States National Health and Nutrition Examination Survey to examine the association between education and weight change where weight change was measured as both a continuous and as a categorical outcome. While the authors did not specifically look at the impact of different weight change modelling on research findings, the results of their study showed slight differences in findings when weight change was modelled as a continuous versus categorical outcome. In contrast to our study where we found no clear pattern between education level and average weight change after adjusting for covariates, the two US studies found that, after adjusting for multiple covariates, mean weight gain was slightly higher in men and women with a lower education level (12th grade or below) than in those with higher education (above 12th grade). When the authors modelled weight change in categories (major weight gain and major weight loss based on change in BMI points), they found no statistical association between education and weight change. While the US studies used weight change based on measured rather than self-reported weight, their sample sizes were relatively small $(\mathrm{n}=1552$ and 4836, respectively) and it is not clear whether these studies were sufficiently powered to detect effects particularly in analyses using weight change categories. In contrast to the US studies, our study sought to test the effect of different modelling of weight change on research findings, and within this we examined the use of different cutpoints to define categories and the use of absolute versus weight change measures, aspects which were not included in the US study designs.

\section{What does this study mean?}

Our results indicate that findings from studies examining factors associated with weight change can vary depending on how weight change is modelled and defined. This limits comparability across study results where different measures have been used and may affect interpretation of individual study results, contributing to inconsistencies in the literature.

We suggest from our results that, where sample sizes allow, weight change should be modelled as a continuous and categorical variable. The common statistical viewpoint is that reducing continuous variables into categories can obscure linear relationships ${ }^{24}$ and result in a loss of information and statistical power. ${ }^{24-26} \mathrm{We}$ counter that, in research studies where weight gain and weight loss are of interest, use of mean weight change alone can obscure important directional information where high proportions of people are either losing or gaining weight within the same exposure group. Modelling weight change both as a continuous and categorical variable is likely to avoid this loss of directional information and increase comparability across studies.

Further, during the planning of analyses, consideration should be given to whether weight change is modelled as an absolute or relative measure and to the cut-points used to define categories. Unless baseline weight differs substantially between exposure levels, the relative and absolute weight-change measures are likely to give similar results; however, the two different measures lend themselves to different research questions and purposes, whether it be for clinical use or for a public health message. ${ }^{4}$

This study was intended to compare results of the association between education and other exposures and weight change, when the definition and modelling of the outcome measure is varied. We did not aim to investigate causal relationships between weight change and other factors and we caution against such interpretation.

\section{Unanswered questions and future research}

The results and conclusions of this paper should be tested by replication, particularly in different datasets and in studies where weight is measured at multiple time points. Further, we did not examine whether inconsistencies between research studies may also be due to differences in how exposure variables were modelled and defined.

\section{CONCLUSIONS}

To the best of our knowledge, this is the first empirical study to directly test whether research results of factors associated with weight change differ according to how weight change is defined and modelled. Specifically, where factors are associated with weight loss and weight gain, continuous measurement of weight gain obscures the direction of the weight change. To build a more complete picture of the relationship between weight change and various factors, we suggest, where possible, that weight change should be modelled as a continuous and categorical variable. Further, consideration should be given to the cut-points used to define categories, as these can result in changes in the magnitude of the effect size; also, when baseline weight substantially differs between exposure groups, consideration should be given to whether absolute or relative change is used. Above and beyond this, agreed definitions for clinically significant weight loss, weight maintenance and weight gain would greatly improve the practical application of research and comparability between studies.

Acknowledgements This research was completed using data collected through the 45 and Up Study (http://www.saxinstitute.org.au). The 45 and Up Study is managed by the Sax Institute in collaboration with the major partner Cancer Council NSW; and partners: the National Heart Foundation of Australia (NSW Division); NSW Ministry of Health; beyondblue; Ageing, Disability and Home Care, Department of Family and Community Services; the Australian Red Cross Blood Service; and UnitingCare Ageing. We thank the many thousands of people participating in the 45 and Up Study. 
Contributors EP primarily designed the study, carried out the statistical analysis and drafted the manuscript. RJK, EB and BR participated in the design of the study and interpretation of results and provided advice on the drafting of the manuscript. All the authors read and approved the final manuscript.

Funding This specific project was part of the Study of Economic and Environmental Factors in health program funded by the National Health and Medical Research Council of Australia (NHMRC) Strategic Award for Preventive Healthcare and Strengthening Australia's Social and Economic Fabric (grant reference: 402810).

Competing interests EB and BR are supported by the NHMRC (Fellowship No. 1042717 and 471429, respectively).

Ethics approval Ethics approval for this project was obtained from the University of Sydney Human Research Ethics Committee and the Australian National University Human Research Ethics Committee.

Provenance and peer review Not commissioned; externally peer reviewed.

Data sharing statement No additional data are available.

Open Access This is an Open Access article distributed in accordance with the Creative Commons Attribution Non Commercial (CC BY-NC 3.0) license, which permits others to distribute, remix, adapt, build upon this work noncommercially, and license their derivative works on different terms, provided the original work is properly cited and the use is non-commercial. See: http:// creativecommons.org/licenses/by-nc/3.0/

\section{REFERENCES}

1. World Health Organization. Obesity and overweight: fact sheet number 311. Secondary obesity and overweight: fact sheet number 311 March 2013. 2013. http://www.who.int/mediacentre/factsheets/ fs311/en/index.htm

2. Ball K, Crawford D. Socioeconomic status and weight change in adults: a review. Soc Sci Med 2005;60:1987-2010.

3. Faith MS, Butryn M, Wadden TA, et al. Evidence for prospective associations among depression and obesity in population-based studies. Obes Rev 2011;12:e438-53.

4. Stevens J, Truesdale KP, McClain JE, et al. The definition of weight maintenance. Int $J$ Obes (Lond) 2006;30:391-9.

5. Banks E, Redman S, Jorm L, et al. Cohort profile: the 45 and up study. Int J Epidemiol 2008;37:941-7.

6. Ball K, Brown W, Crawford D. Who does not gain weight? Prevalence and predictors of weight maintenance in young women. Int J Obes Relat Metab Disord 2002;26:1570-8.

7. Brown WJ, Williams L, Ford JH, et al. Identifying the energy gap: magnitude and determinants of 5-year weight gain in midage women. Obes Res 2005;13:1431-41.
8. Noel PH, Copeland LA, Perrin RA, et al. VHA Corporate Data Warehouse height and weight data: opportunities and challenges for health services research. J Rehabil Res Dev 2010;47:739-50.

9. Berrington de Gonzalez A, Hartge P, Cerhan JR, et al. Body-mass index and mortality among 1.46 million white adults. $N$ Engl J Med 2010;363:2211-19.

10. Korda RJ, Liu B, Clements MS, et al. Prospective cohort study of body mass index and the risk of hospitalisation: findings from 246 361 participants in the 45 and Up Study. Int J Obes (Lond) 2012. Published Online First. doi: 10.1038/ijo.2012.155

11. Whitlock $G$, Lewington $S$, Sherliker $P$, et al. Body-mass index and cause-specific mortality in 900000 adults: collaborative analyses of 57 prospective studies. Lancet 2009;373:1083-96.

12. Ball K, Crawford D, Ireland $\mathrm{P}$, et al. Patterns and demographic predictors of 5-year weight change in a multi-ethnic cohort of men and women in Australia. Public Health Nutr 2003;6:269-81.

13. Lewis CE, Smith DE, Wallace DD, et al. Seven-year trends in body weight and associations with lifestyle and behavioral characteristics in black and white young adults: the CARDIA study. Am J Public Health 1997;87:635-42.

14. (AlHW). AloHaW. The Active Australia Survey: a guide and manual for implementation analysis and reporting. Canberra: AIHW , 2003.

15. Stewart AL, Kamberg C. Physical functioning. In: Stewart AL, Ware JE, eds. Measuring functional status and well-being: The Medical Outcomes Study approach. Durham, NC: Duke University Press: 1992:86-142.

16. Glymour MM, Weuve J, Berkman LF, et al. When is baseline adjustment useful in analyses of change? An example with education and cognitive change. Am J Epidemiol 2005;162:267-78.

17. Shea S, Rabinowitz D, Stein AD, et al. Components of variability in the systolic blood pressures of preschool children. Am J Epidemiol 1998;147:240-9.

18. StataCorp. Statabase Reference Manual Release 12. Texas: Stata Press, 2011.

19. Long JS, Freese J. Regression models for categorical dependent variables using Stata. College Station, TX: Stata Press, 2006.

20. Gorber SC, Tremblay M, Moher D, et al. A comparison of direct vs. self-report measures for assessing height, weight and body mass index: a systematic review. Obes Rev 2007;8:307-26.

21. $\mathrm{Ng} \mathrm{SP}$, Korda R, Clements $\mathrm{M}$, et al. Validity of self-reported height and weight and derived body mass index in middle-aged and elderly individuals in Australia. Aust N Z J Public Health 2011;35:557-63.

22. Kahn HS, Williamson DF. The contributions of income, education and changing marital status to weight change among US men. Int $J$ Obes 1990;14:1057-68.

23. Kahn HS, Williamson DF. Is race associated with weight change in US adults after adjustment for income, education, and marital factors? Am J Clin Nutr 1991;53(6 Suppl):1566S-70S.

24. Altman DG, Royston P. The cost of dichotomising continuous variables. BMJ 2006;332:1080.

25. MacCallum RC, Zhang S, Preacher KJ, et al. On the practice of dichotomization of quantitative variables. Psychol Methods 2002; 7:19-40.

26. Fedorov V, Mannino F, Zhang R. Consequences of dichotomization. Pharm Stat 2009;8:50-61. 